\title{
Una derrota profética de la política progresista en América Latina
}

\section{Resumen}

La instauración de democracia, la construcción de lo que significa la participación ciudadana y un discurso que tiende a ser cercano a la lucha por y para el pueblo han quedado despojados de toda credibilidad. Las dicotomías entre izquierda- derecha entran en tensión porque el diálogo cercano que parecen tener los dirigentes en los gobiernos que se identifican de izquierda y no precisamente izquierda tradicional, dirigen sus acciones hacia la expropiación de tierras para la potenciación y seguridad del capital privado. Este tipo de acciones han ido formando una serie de inconformidades entre las personas que han confiado en sus capacidades de ejercer el poder a través de la justicia, como consecuencia existe un desequilibrio político que pone en crisis sus discursos sobre democracia y la manera de hacer política.

Palabras claves: Extractivismo, populismo, democracia

Uno de los grandes debates que está causando revuelo en América Latina es la crisis que enfrentan los gobiernos progresistas. Estos gobiernos han surgido de rebeliones populares que exigían una democracia real que redujera las agresiones a los derechos humanos y de territorios que estaban siendo controlados por la fuerza de la dominación imperial: el capitalismo.

Sin embargo, la lucha por el poder y algunas acciones y decisiones emprendidas para la mejora económica y social de los países, causan confusión de los discursos oponentes entre izquierda y derecha, provocando así un malestar en las sociedades porque ya no existe una distinción clara entre derecha/izquierda. Pero

\begin{abstract}
The establishment of democracy, the construction of what means citizen participation and a discourse that tends to be close to the struggle for and on behalf of people, it is deprived of all credibility. The dichotomies between left and right come into tension because the close dialogue that seems to have the leaders in the governments that identify themselves as leftist and not just the traditional left address their actions toward the dispossession of land to assure and empower private capital. This type of actions has generated a kind of unconformity among people who have relied on the ability of such governments to exercise power through justice, as consequence there is a political imbalance that make crisis on their speeches about democracy and the way of do politics.
\end{abstract}

Key Words: Extractivism, populism, democracy

de existir dicha distinción sería simplemente un antagonismo bien establecido.

Uno de los principales fallos de discurso de los gobiernos Progresistas, es que su gestión social, política y económica beneficia a los que poseen los medios de producción, que son los dueños de bancos o empresarios, que generalmente son parte de pequeños grupos oligarcas a quienes se les brinda un trato especial protegiendo la propiedad privada de

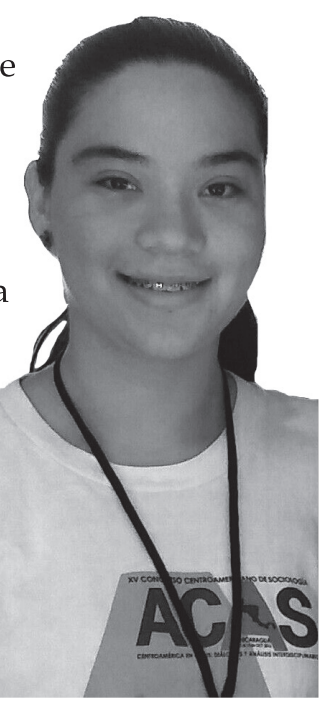

Br. María Ruth Del Carmen.

1 Actualmente, quinto año de sociología en la Universidad Centroamericana UCA (Nicaragua). Asistente de Investigación en el Programa Interdisciplinario de Estudios de Género (PIEG-UCA). 


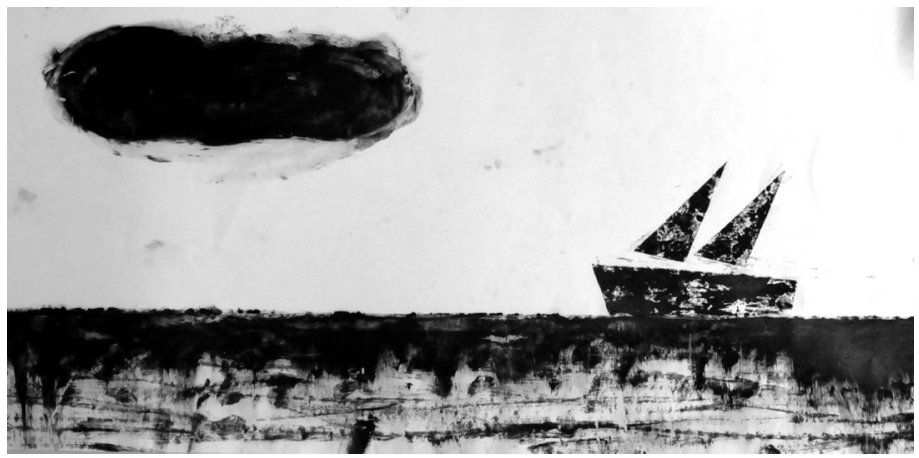

Autor: Denis Núñez

estos, garantizándoles seguridad y privilegios en sus inversiones. Por lo tanto en este ensayo se pretende comprender y explicar algunos factores, como el extractivismo exportador, como detonantes del fin de ciclo, así como la prevalencia del discurso de atraer inversiones extranjeras como fuentes de empleo y desarrollo. Los gobiernos con discursos Progresistas han quedado despojados de credibilidad, al responder a la crisis económica y política con ajustes contra el pueblo, para tratar de salvar las ganancias del capital nacional acumulado.

Asimismo, todo parece haber iniciado con la derrota política en Argentina y la sucesión de Nicolás Maduro, en Venezuela, tras la muerte de Hugo Chávez, sumando a esto decisiones políticas que tienen que ver con el apoyo a la inversión extranjera en proyectos de minería, que han proclamado la guerra entre la sociedad civil y el Estado. En este sentido la socióloga Maristella Svampa (comunicación personal, Muñoz 2016), afirma que: "la consolidación de una matriz extractivista ha mostrado sus limitaciones en un contexto de fuerte caída de los precios internacionales de los comodities, insertando así a los diferentes países en una crisis económica cada vez mayor".

Maristella, explica que el extractivismo se ha convertido en uno o quizás la principal fuente de ingresos para los gobiernos progresistas y que estos no han sido capaces de afrontar la crisis de la caída de los precios internacionales de los commodities, agudizando no sólo la crisis económica que impera en este ciclo sino también el rechazo popular que no se limita a estar presente en las elecciones y encuestas sino también en los diferentes grupos organizados, como el de los jóvenes, que están desesperados por la situación económica, social y política que están viviendo. Pese a las organizaciones de la sociedad civil que están en contra de que continúen el despojos de territorios para la obtención de beneficios de materia prima, como ocurre con la práctica de la minería, los diferentes gobiernos parecen estar decididos en mantener de cierta manera su discurso de progreso a través de la inversión extranjera.

Esta situación se torna cada vez más complicada de mantener, y es que los diversos movimientos sociales ya no quieren escuchar más sobre el discurso de los beneficios económicos a través de inversiones ni mucho menos de la minería y despojo de sus tierras. Un ejemplo de esto es el caso de la región de Islay, al sur de Perú, en donde se protagonizó un levantamiento popular en contra de un proyecto minero multinacional que afectaría su agricultura.

Cabe mencionar que en la mayoría de las situaciones de tensiones entre ciudadanía y Estado la salida más fácil, como estrategia política para garantizar la democracia, ha sido el populismo; Ernesto Laclau (2005), afirma que "el populismo es una forma de pensar las identidades sociales, un modo de articular demandas dispersas, una manera de construir lo político".

Realmente el populismo como una estrategia democrática, para un momento de inestabilidad de un Estado, puede ser un elemento indispensable y no necesariamente debe ser percibido como algo negativo, ya que se ha visto en algunos gobiernos latinoamericanos que ha sido efectivo.

Sin embargo, hasta qué punto este populismo moderno del que habla Lacau va a seguir funcionando como una estrategia asistencialista y una especie de calmante para los sectores vulnerables, sobre todo en esta crisis que cada vez se está agudizando más.

Ahora lo importante es interrogarse si verdaderamente el populismo contribuye a una formación de ciudadanía y si está orientado a la participación autónoma. Es necesario incluir otras estrategias políticas y darle un voto de confianza a las capacidades administrativas del Estado y dejar vislumbrar la posibilidad que pueden llegar a ser Estados aceptables, capaces de responder a cualquier crisis. 


\begin{abstract}
Retomando el debate sobre extractivismo como un detonante para esta crisis de fin de ciclo, Maristella tiene una definición sobre el contexto actual en el que se desenvuelve: “...Extractivismo es un patrón basado en la sobreexplotación de recursos naturales en gran parte no renovables..." (Svampa, SF p. 5).
\end{abstract}

Para Maristella el

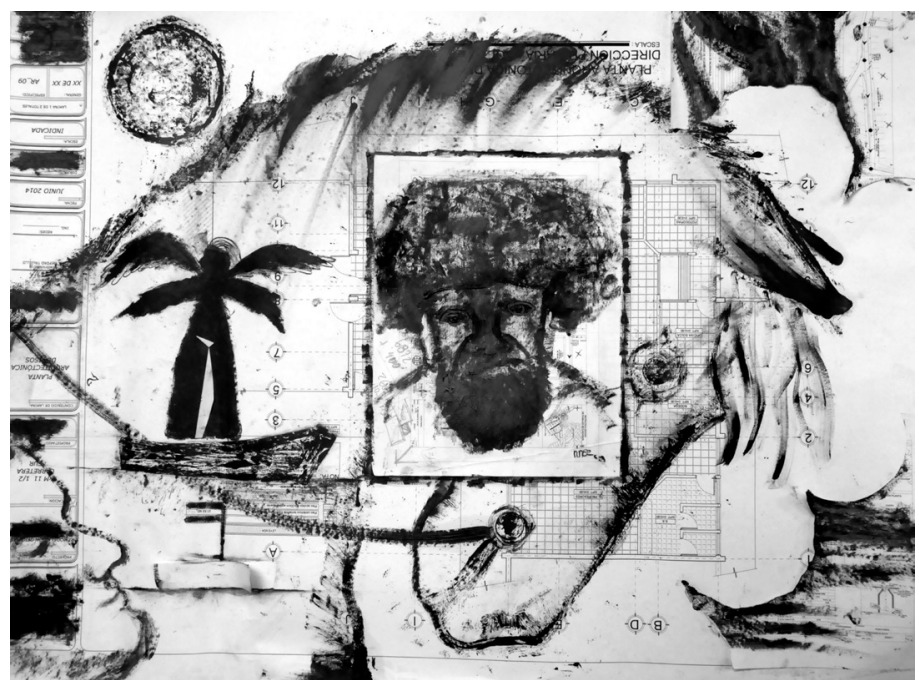

Autor: Denis Núñez
La primera limitación radica en que el carácter pos neoliberal y de izquierda es cuestionable por aceptar y ser partícipes de la globalización. La segunda limitación es que cuestiona que el carácter neoliberal y de izquierda es de índole eco territorial y reviste un carácter sistémico; y la tercera es más política institucional, a través de la concentración del poder político.

En este sentido se puede identificar en un caso concreto a que están basadas en la explotación de los recursos y que esto ha venido a ser, como diría Leff, un argumento fundamental para legitimar el orden existente, tangible y objetivo. Hasta cierto punto es considerable que durante los procesos de modernización y avances tecnológicos, las sociedades han sufrido grandes cambios pero la naturaleza, principalmente, ha sido utilizada como recurso para el beneficio económico de un sector específico.

A pesar de todos los marcos regulatorios que surgen para proteger los recursos y los territorios, el capitalismo sigue su camino, y el error más grande ha sido la relación izquierda derecha en aspectos económicos para su propio beneficio.

Por lo tanto, una de las consecuencias de la actual inflexión extractivista ha sido la explosión de conflictos socio-ambientales, visibles en la potenciación de las luchas ancestrales de movimientos indígenas y campesinos, así como el surgimiento de nuevas formas de movilización y participación ciudadana centradas en la defensa de los recursos naturales. (Svampa, et al 2011).

En el marco de la crisis que enfrenta el progresismo, parece ser que no todos los gobiernos la viven de la misma manera, y los que aún han logrado mantenerse en el poder, como es el caso de Nicaragua, hay tres limitaciones fundamentales, según Svampa, que caracterizan a los gobiernos progresistas realmente existentes.
Nicaragua, caracterizándolo en la segunda limitación que está referida al eco territorio. En este momento, la mayor debilidad del gobierno nicaragüense está centrada en la lucha por la preservación de la reserva de Bosawás, la cual ha sido protegida desde hace mucho tiempo por los pueblos originarios y hoy se encuentra amenazada por diversos agentes a los que se les ha otorgado una libre entrada a la reserva, para posesionarse del territorio que más les convenga con el objetivo de obtener ganancias económicas.

Cabe destacar que Bosawás es la reserva forestal más grande de América Central y la segunda más grande de América Latina. Asimismo, alberga importantes depósitos de agua, así como diversidad de especies forestales y una fauna abundante. Pese a las denuncias realizadas por los indígenas originarios de los territorios aledaños a la reserva y a las denuncias de ambientalistas, el gobierno no ha ejecutado las acciones pertinentes que el caso amerita.

Lamentablemente la deforestación y la colonización acelerada de los territorios de los pueblos indígenas siguen a flor de piel. Maristella afirma que: "la expansión del extractivismo ilustra la relación inherente entre modelos de mal desarrollo, cuestión ambiental y regresión de la democracia" (Svampa, 2015).

En esta afirmación se puede observar el extractivismo personificado en las malas decisiones por 


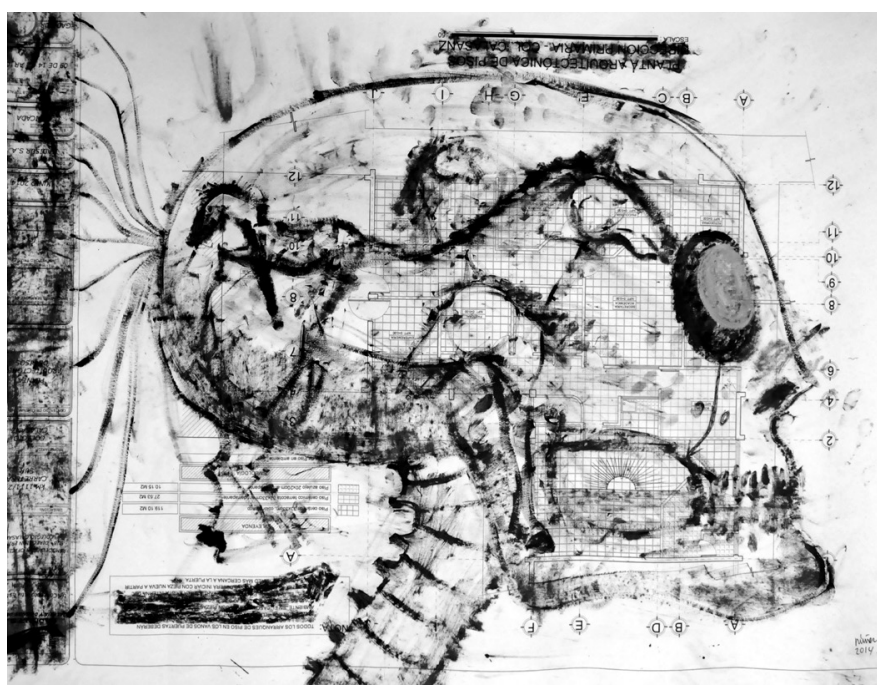

Autor: Denis Núñez

parte del Estado nicaragüense, por no tomar en cuenta el significado que tiene la reserva en cuanto al valor de biodiversidad y generadora de vida.

Sin embargo, el problema no es sólo el impacto ambiental, sino también las tensiones que genera en las relaciones entre el gobierno, los pueblos indígenas que están siendo afectados y los diversos movimientos sociales ambientalistas que no están de acuerdo con la falta de pronunciación del Estado, al respecto.

Hay que resaltar que es un atropello a los derechos de los pueblos indígenas que no se respeten sus territorios, sus formas de organización, costumbres $\mathrm{y}$ tradiciones.

En cuanto a la regresión de la democracia de la que habla Maristella, realmente en los últimos tiempos se ha visto estratégicamente controlada por el Estado, teniendo en cuenta que la democracia no solo se limita al ejercicio electoral, sino a la participación activa de la población lo cual se puede traducir a una definición un poco más moderna de ciudadanía, ya que esta existe por la participación activa de la sociedad.

Es posible que esta situación de crisis que están enfrentando los Gobiernos progresistas sea irreversible, pero para poder pensar hoy la política y comprender la naturaleza de estas nuevas luchas y la diversidad de las relaciones sociales que la revolución democrática ya ha desplegado, es indispensable desarrollar una teoría del sujeto como agente descentrado de un sujeto construido de una multiplicidad de objetividades. (Mouffe, 1999 p31)

Si ya se reconoce el problema político casi insostenible que envuelve a Latinoamérica, es preciso pensar o repensar una propuesta diferente a lo que históricamente se ha venido siguiendo como un patrón universal, característico de una herencia ideológica política de izquierda, que no ha hecho más que reproducir acciones desarrollistas, propias del capital, que no concuerdan con un discurso dirigido para el beneficio de la clase trabajadora ni parece estar a favor de una ética eco socialista que apoya la preservación de los recursos, sino que reproduce el discurso de capitalismo verde, que realmente es invisible en cuanto a acciones.

Realmente no se puede afirmar el futuro de los Gobiernos Progresistas, pero, si algo es seguro, es que hay que pensar en la posibilidad de re pensar la izquierda tomando en cuenta otras estrategias y elementos que den respuesta a todo un imaginario político.

Chantal y Ernesto Laclau proponen una reformulación del proyecto socialista desde una democracia radical y la definición de la modernidad en el nivel político, ya que es de allí donde las relaciones sociales toman forma y se ordenan simbólicamente. (Mouffe, 1999). Esta lectura de la reformulación del proyecto socialista debe hacerse desde el reconocimiento del poder y el antagonismo como rasgos propios de lo político.

Por esa razón Mouffe plantea la existencia de un nuevo sentido común, ya que no se trata de establecer alianzas entre intereses dados sino de transformar la identidad de las fuerzas. En este sentido, es desde la filosofía política que se construirán otras posiciones que van surgir desde las subjetividades para mostrar otros tipos de realidades.

Es difícil aceptar que los problemas que han afectado al progresismo no han sido esbozados y han pasado desapercibidos cuestionando la corrupción y la ineficiencia, facilitando así la restauración derechista que hoy amenaza todo un sistema que luchó por la erradicación del Capitalismo y hoy actúa como tal. 
Quizá repensar la izquierda en Nicaragua no sería tan fácil de proponer a futuro porque los intereses personales de los gobernantes están más relacionados a los intereses de un socialismo-capitalista, que solo se preocupa por la concentración del capital y el valor de los recursos en términos económicos.

\section{Bibliografía}

Laclau, E (2005). La Razón Populista (Buenos Aires y México). FCE.

Wanderly, F (2011). El Desarrollo en Cuestión: Reflexiones desde América Latina. (Plural Ediciones). La Paz Bolivia.

Mouffe, C (1999). El Retorno de lo Político: comunidad, ciudadanía, pluralismo, democracia radical. (Paidós). Barcelona, España.

Muñoz, G (2016). Fantered.www.fanterd. $\mathrm{com} / \mathrm{q}$ =maristella-svampa $\quad$ y-crisis-cicloprogresista-en-latinoamerica.

Leff, E. (1998/2002). Saber Ambiental: racionalidad, sustentabilidad, complejidad, poder. (México: siglo XXI).

Svampa, M, Acselrad, H,Machado H, Acosta A, Machado $\mathrm{D}$ et al (2012). Movimientos socioambientales en América Latina.(Buenos Aires). CLACSO. Recuperado de http://biblioteca.clacso.edu.ar/ clacso/osal/20120927103642/OSAL32.pdf

Svampa, M.(SF). Reconfiguraciones del clivaje Norte/ Sur: Una mirad desde la geografía de la extracción. Recuperado de http://www.cetri.be/IMG/pdf/ maristella_svampa_46000_esp.pdf.

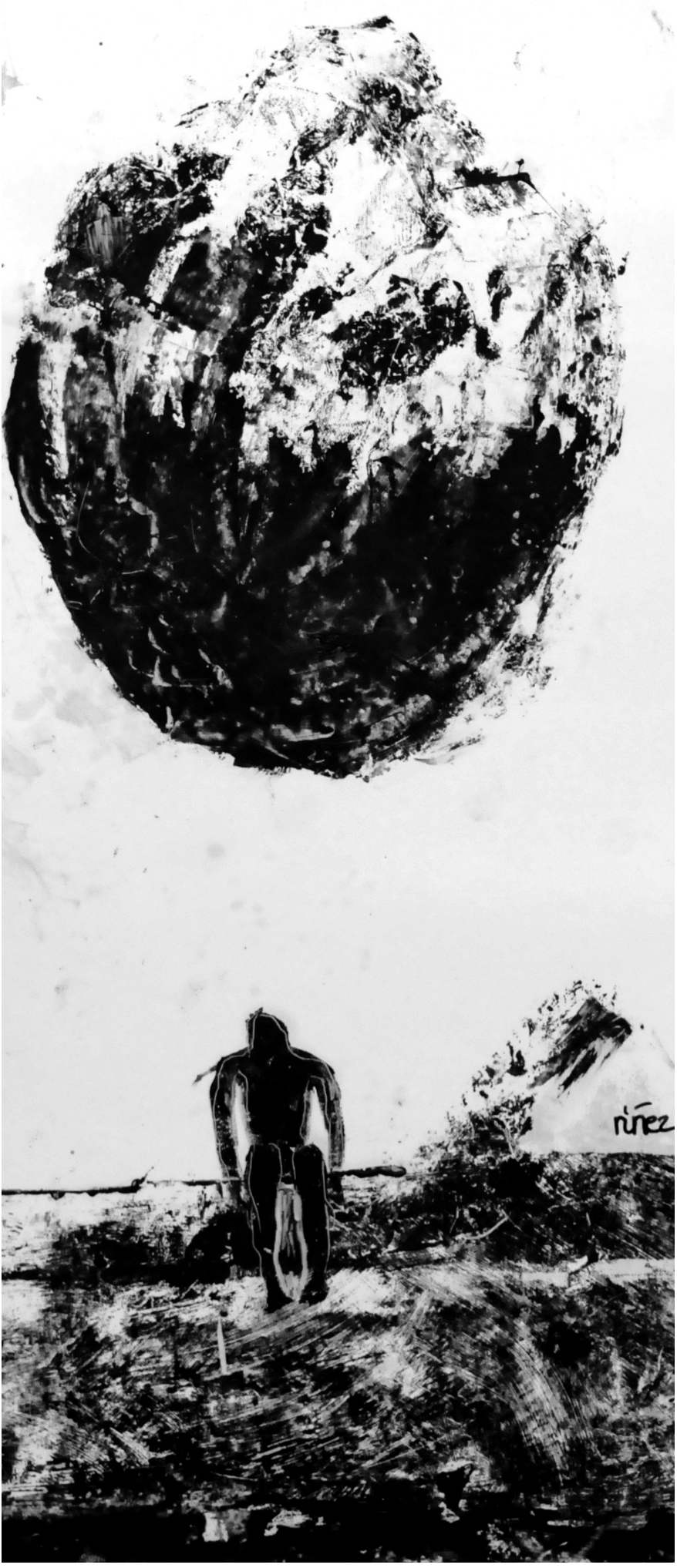

Autor: Denis Núñez 